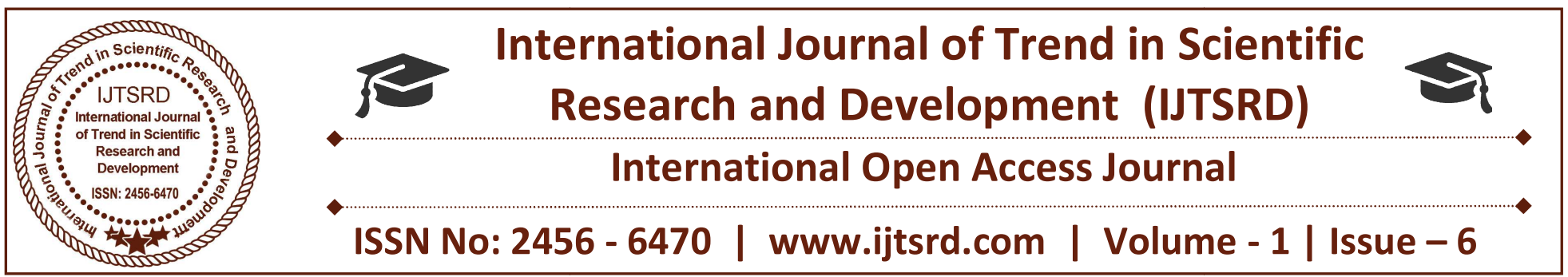

\title{
Benefits and Issues of Cloud Computing in Accounting
}

\author{
Mr. Abhijit Mohanty \\ Research Scholar, Department of Business \\ Administration, Utkal University, \\ Vani Vihar, Bhubaneswar
}

\author{
Dr. Ajit Kumar Mishra \\ Lecturer, Department of Business Administration, \\ Utkal University, \\ Vani Vihar, Bhubaneswar
}

\begin{abstract}
According to practitioners' opinion, any business can witness extensive benefits from using cloud-based solutions. The intuitive design, the possibility to access real-time information and several other advanced features make accounting accessible for both experts (accountants) and non-experts (small business owners). The study has made an attempt to find out the benefits and issues of cloud accounting on accounting and decision making abilities of the firms. The paper is a qualitative research, based upon the most relevant literature on this topic. The literature on this subject is mainly built on practitioners' studies and handbooks, surveys conducted by specialized research companies or by cloud service developers. The benefits are more in compared to the issues involved in using cloud based accounting system. This paper focuses on the impact of cloud accounting on each actor in the entire business area.
\end{abstract}

Keywords: cloud computing, cloud accounting, risks and benefits

\section{INTRODUCTION}

Cloud computing is first and foremost a concept of distributed resource management and utilization. NIST (National Institute of Standards and Technology) defines it as a "model for enabling ubiquitous, convenient, on-demand network access to a shared pool of configurable computing resources (e.g., networks, servers, storage, applications, and services) that can be rapidly provisioned and released with minimal management effort or service provider interaction." (Mell \& Grance, 2011) It aims at providing convenient endpoint access system while not requiring purchase of software, platform or physical network infrastructure, instead outsourcing them from third parties. The arrangement may beneficially influence competitive advantage and flexibility but it also brings about various challenges.

As stakeholders require ubiquitous access to and protection of data affecting their business operations, cloud became a valid option for cost-effective data redundancy, off-site backups, big data storages or IT outsourcing. However, nature of cloud computing itself may be in violation of corporate security policies regarding data retention and ability to guarantee security of physical network infrastructure. Some organizations even object to the notion of not having direct control over where the data resides. Addressing these issues is essential to understanding cloud architecture paradigm.

This increasing pace of change promoted by cloud solutions has also reached the accounting domain. As expected, cloud service providers have developed cloud-based accounting applications, which have considerable advantages. Today, accounting in the cloud is a new business reality, powered by cloud computing technology. Also known as cloud 
accounting or online accounting, this software acts like accounting applications installed on users' computers, but it is performed on servers offering online services and users can access them through web browsers. This way, accountants or business owners can connect to their financial affairs from any location, over the Internet.

Regarding the development of technology, companies and therefore the accounting department are generally influenced by: the digitisation of business, the intense potential created by the internet, the implications of big data and the growing importance assigned to data mining. In this context cloud computing made its way and created new business models. The impact of cloud computing is presently undisputed and will provide the basis for future metamorphosis of the economic field.

Technology is revolutionising how accountants work. The major driver of this change is cloud computing which is enabling not only companies, but their accountants with better and faster access to business intelligence that they can then use to advise clients. Cloud computing allows a company to access applications from an offsite provider via the internet, rather than from company-owned and maintained hardware and software. This provides software as a service, which in turn allows businesses to pick and choose best of breed software, bringing together online accounting, inventory, business intelligence, CRM, payroll and many other packages.

With the introduction of online accounting software we can now access the client information on-line in real time. This has made the accounts preparation process more timely and efficient, as well as opening up access to more up-to-date and detailed business information. The benefits of having your financial statements prepared sooner are many. Whether it is meeting banking covenants, quickly understanding how your business has truly traded or assisting with forecast preparation.

Less time taken preparing accounts also leaves your accountant able to spend more time on understanding your business and providing insightful advice. Access to the information online also means that this advice is based on real-time information. On-line access has the added benefit of encouraging greater collaboration between businesses and their advisors which in turn leads to better governance. The key drivers for your business can be highlighted and tracked on a dashboard. Tracking these key performance indicators drives better business management and can be viewed simultaneously by your advisors. Decisions can be based on current data and allow boards the flexibility to meet virtually. It is well documented that good governance is crucial to the SME sector. So while you will still need great people on your board that are willing to challenge and bring their experience to bear, technology is playing an increasingly important role in assisting more effective governance. Talk to your advisor about the Cloud Computing options that are available and most relevant for your business and how you can maximise any investment you make in this new technology.

The world of accounting software is rapidly shifting towards cloud computing. A great number of accounting software vendors have already moved their products to the cloud and provide different forms of cloud accounting solutions. Large accounting companies like KPMG, PricewaterhouseCoopers, Ernst \& Young, Deloitte, Sage or SAP have each presented their own cloud offer and also published White Papers that present the benefits and functionalities provided through different types of services. A list of cloud accounting solutions would also include Financial Force.com, NetSuite, Microsoft Office 365, FreshBooks, Liquid, QuickBooks Online, Myob, Xero, Aqilla, Mint.com or Waveaccounting, each of them ensuring specific or custom-made functionalities. The cloud accounting market is beginning to rise by delivering solutions that are seriously worth taking into account. On the other hand, companies from all over the world benefit from cloud accounting services as customers.

\section{LITERATURE REVIEW}

Armbrust et al (2009) postulate: "Cloud Computing refers to both the applications delivered as services over the Internet and the hardware and systems software in the data centres that provide those services. The services themselves have long been referred to as Software as a Service (SaaS). The data centre hardware and software is what we call a Cloud." The definition provides a comprehensive, holistic view of cloud's elements while mentioning one of several "... as a Service" models evolved when the paradigm became commercially viable for cloud operators to monetize: IaaS (Infrastructure as a Service), PaaS (Platform as a Service), and SaaS, each 
of which differs in parts of hardware/software infrastructure managed by the provider and by the client. It is inherently part of a SLA (Service-Level Agreement). Borenstein and Blake (2011) sees it as "...the use of fast, high-bandwidth Internet connections to deploy services that are centrally maintained, often by third parties, and thus minimize the cost and difficulty of IT administration and support for the organizations that consume those services." Emphasis on high-speed internet connection is of primary concern to applications requiring large data sets, possibly even Big Data databases spanning terabytes processed by means of KDD (Knowledge Data Discovery), almost exclusively in a distributed fashion. Transferring such data poses a logistical issue requiring calculations as to whether it is viable to utilize cloud at all, or rather resolve to local data processing repositories, as well as security (data encryption) and throughput (bandwidth constraints) limitations in case the cloud is used. Foley (2008) provides this explanation: "Cloud computing is on-demand access to virtualized IT resources that are housed outside of your own data centre, shared by others, simple to use, paid for via subscription, and accessed over the Web." Interfacing with the cloud is primarily done via a web browser with many vendors allowing access also via CLI (Command Line Interface) or dedicated clients executed on desktop stations, mobile phones or combination of both.

According to Saasu (2013), Cloud accounting is also referred to as -online accounting and it serves the same function as accounting software that you would install on your computer, except it runs on our servers and you access it using your web browser, over the Internet. Your data is securely stored and processed on our servers - or -in the cloud. This means you are able to access your business financials from anywhere and using any device, as long as you are connected to the internet. After the deployment of cloud computing in different types of businesses, at a certain point, it has also reached the accounting field. A company's accounting should not be apart from the business itself, but it should rather be an integrant component, with an essential role in the business's dynamics. In order to achieve this objective, the accounting model should be 'co-developed', thus adding value both for the financial aspects and for the business itself (Hatherly,2013) Traditional applications for financial accounting are sometimes complex and too expensive, especially for a small or starting business. They also require storage capacity, Internet bandwidth, and a specialized IT staff to configure, install and update the accounting software (Mihalache, 2011). Today's accounting model implies ease of access, customization, collaboration and ultimately, the use of the Internet through cloud computing. The basic principles that drive cloud computing, combined with the activities carried out by accounting software companies, have led to the emergence of cloud accounting. This concept, also referred to as 'online accounting', involves the same functionalities as an accounting software installed on the client's computer, but which actually runs on the CSP's servers. Basically, it provides accounting services by means of cloud computing solutions.

(Dimitriu and Matei, 2014) studied is the impact of the cloud computing paradigm on the accounting domain. They highlighted different points of view and definitions assigned to the concept of 'cloud accounting', and also, the benefits and possible risks determined by the adoption of these services, particularly in relation to the accounting department. (Dimitriu and Matei, 2015) studied the benefits associated with Cloud accounting. They highlighted the impact of cloud accounting on each actor in the entire business area.

Howlett (2013) states that accounting on the cloud has often been characterized as something that will never happen or at least no time soon, however, if you look at the SME market, it is transforming the crusty world of professional accounting.

According to Nixon (2012) "Accountants who do not embrace the benefits of cloud technology for SME's should see the new technology as a threat to their core business. The facts are that cloud based technology can and does reduce the time needed on compliance services. This drives competition and price pressure for compliance services. However, with real time data the Accountant can be more relevant by offering planning, monitoring and other advisory services. It's a win-win if the Accountant uses the data to add value. If they do not then they will lose business".

\section{RESEARCH OBJECTIVES AND METHODOLOGY}

The paper is a qualitative research and it is based upon the most relevant literature on this topic. The literature on this subject is mainly built on 
practitioners' studies and handbooks, surveys conducted by specialized research companies or by cloud service developers. The objective of the study is to highlight the major benefits and issues/risk involved in cloud accounting in relation to accounting department.

\section{BENEFITS AND RISK/ISSUES OF USING CLOUD ACCOUNTING}

According to practitioners' opinion, any business can witness extensive benefits from using cloud-based solutions. The intuitive design, the possibility to

access real-time information and several other advanced features make accounting accessible for both experts (accountants) and non-experts (small business owners). By taking a systematic approach to risk assessment, including creating effective policies for cloud usage and a risk response plan, companies can experience the leverage of this new technology and increase operational efficiency (Kinkela and College, 2013).

\subsection{Benefits of using Cloud Accounting}

There are numerous benefits to cloud accounting and progressive business owners are enjoying them. Here are a few of the benefits:

a. Anytime, anywhere access: The first benefit of adopting cloud accounting is that is can be access $24 / 7$ and the user can access it from any part of the world. The accounting software and operating results are made available to the users from a browser or mobile device. This is something that you can't do with today's desktop accounting solutions.

b. Better security: The second benefit is that it ensures high security checks in spite every activity is done on online platform. Most of the cloud accounting software is run from a data centre, which offers multiple levels of security to protect the software and data. The typical data centre has significantly better security than most small businesses.

c. No installations or updates required: The cloud computing enables the end users not to put more investment in purchasing hardware in order to store and maintain the data at their own location. Rather the cloud accounting vendors maintain the software and install the updates, which cost less in compare to having own system for storing huge amount of data. Because the software is provided over the Internet, users are always able to access the updated version of the technology.

d. Savings staff: having your own IT infrastructure combined with the employment of highly qualified specialist managing and monitoring the work of individual departments. When you move to a cloud computing infrastructure, the responsibility for ensuring access to services is on the supply side. This enables a significant reduction in IT staff.

e. Automatic backups: Holding huge amount of important data in one physical place becomes a challenge for organisations. By adopting an online accounting solution, there is no hardware (hard drives, servers or external memory) to maintain. The cloud vendor assumes responsibility for system backups. The data is often stored in multiple data centres that are in geographically diverse locations. It provides an online platform to store unlimited data, round the clock processing capacity and automatic backup for the customer's data. It also allows client companies to effortlessly add or remove capacity, depending on its needs and without other expenses.

f. No start-up costs: The costs involved in using accounting software include both the up-front investment and the later maintenance expenses. A company's initial investment can be substantially reduced through cloud accounting offerings because, with this business model, there is no hardware or software licenses to purchase. The Cloud accounting applications are rented not purchased. They do not require a small business to invest in servers or software.

g. Platform agnostic: Another popular feature of cloud accounting is that is compatible with various operating systems and web browsing software. The client can access the application through Mac, Linux or Windows. Similarly it does not require any specific web browsers to run it on the client's system. The client can run it through Chrome, Internet Explorer or Firefox. The Cloud accounting applications are delivered via a web browser and typically support all popular platforms.

h. User friendly: It can be customized highly and many things can be moulded as per customer's requirement making accounting language and 
features, easy to understand and use. It also helps accountants to generate real-time financial reports while allowing them to concentrate on analyzing data and ensuring insights on financial aspects. It enables companies to share their financial information with their clients in real-time, accordingly creating improved communication and collaboration.

i. Cost Effective: The client has to spend more money if activities like accounts receivable, vendor payments and payroll are being processed manually. A manual system for customer receivables or vendor payables is rife with inefficiencies. A cloud-based system can cut the number of steps required to pay an invoice or receive payments from your credit customers. By automating many of the processes, a cloud-based system can cut the time to pay bills and get paid by one-third or more. You will also save the money you are spending on postage, check stock, printers and supplies. It is much easier to manage cash flow with a cloud-based accounting system that will allow you to take advantage of early payment discounts or stop paying late charges.

j. Increased productivity: Cloud-based software ensures the business continuity through several means. The automated back-up of the financial data is performed as a scheduled task (daily, weekly or monthly, as the customer requires). Even if the user's laptop is stolen or malfunctioning, there is no risk of losing data; the same information can be accessed from another device. Before cloud computing, productivity stopped once the business owner and their employees left the office. By using online accounting, the business can go on, thus providing business continuity.

\subsection{Risks/issues of using Cloud Accounting}

Considering the fact that today's economic environment is highly competitive and challenging, each business is very careful when it comes to sharing their financial data. In fact, owning the right information at the right time is a very powerful tool in the business field. The world of cloud accounting is not without risk. These solutions are new and require that you perform the necessary due diligence to determine if the solution is right for your business. Here are a few of the risks:

a. The vendor goes away: Every day new vendors are entering into the market with a promise to provide better services at low cost. But most of them won't last for very long period of time. Due to various reasons they vanishes from the market and the clients gets disconnected from the data. Over a decade ago, it is experienced a tech bubble where vendors were here one day and gone the next. The same risk exists with cloud accounting vendors. It is important to have a contingency plan in order to keep things moving.

b. You don't have Internet access: It is a web based system and it requires uninterrupted internet access around the clock to make things happen. Cloud accounting vendors are accessible from anywhere and anytime assuming that you have a connection to the Internet. But if you find yourself without internet access, you will not have access to your accounting data.

c. Security breach: Five or six years ago, when cloud systems were first coming onto the market, security was definitely the overriding concern. But that concern has gradually been pushed down the line as people realize cloud systems can be very secure, and in many ways are more secure than existing systems based on office servers. Cloud accounting software and your data both live on the Internet. There is a risk that someone could gain access to your data.

\section{RECOMMENDATIONS}

The cloud has already conquered almost every business area, but it seems that the accounting profession is skeptical about this new model. According to some accountants, cloud-based software is an obvious threat. Of course, it could be considered a threat for those who are not willing to adapt and to clearly comprehend the benefits involved. As we all know, people fear what they do not understand. This business model is not implying that accountants are excluded from the branch. In fact, these solutions are meant to simplify the accountant's tasks and to optimize the business workflow. Cloud-based applications are not designed to replace the human factor from the business activity. The accounting profession should be receptive and evolve in accordance to the reality that we are living today. Accountants need to experience a different point of view and welcome the assistance given by this innovative 21 st century technology. They also need to move towards a more interactive service and efficiently meet the informational needs of businesses that are sometimes struggling to assess the way 
forward. Accountants need to be able to offer realtime insight into profitability. Cloud accounting offers the alternative to shift from paper-based financial statements to real-time financial dashboards. Cloudbased accounting software can give companies the chance to transform the client relationship by improving collaboration and communication. Accountants can enable business partners to access accurate and real-time data from anywhere through an internet connection. There is a clear opportunity for accountants to step up and play a vital role in enabling a new level of business insight that could transform the performance of businesses especially for small companies.

\section{CONCLUSION:}

In such a dynamic and challenging environment as the economic field, companies are considering a new way for doing business. The cloud concept is getting more popular as time goes by and increasingly more companies are adopting cloud-based software in order to improve their efficiency and to experience many other benefits. The cloud accounting model enables all business participants (business owners, accountants, auditors and clients) to closely collaborate by accessing up-to-date financial data in the same time, via the internet. If accountants give technology the chance to prove its worth, the accounting profession could eventually act as a worldwide standardized entity and take businesses to the next level of efficiency.

\section{REFERENCE:}

1). Mell, P., and Grance, T., 2011: The NIST Definition of Cloud Computing (Draft). Recommendations of the National Institute for Standards and Technology, [online], NIST, http:/csrc.nist.gov/publications/drafts/800-145/DraftSP-800-145_cloud-definition.pdf

2). Armburst, M. et al., 2009: Above the Clouds: A Berkeley View of Cloud Computing", [online],
University of California, Berkeley, http://www.eecs.berkeley.edu/Pubs/TechRpts/2009/E ECS-2009-28.html Borenstein, N., and Blake, J., 2011: Cloud Com

3). puting Standards: Where's the Beef?, IEEE Internet Computing, Vol. 15, No. 3, pp. 74-78

4). Foley, J., 2008: A Definition of Cloud Computing, [online], http://www.informationweek.com/cloudcomputing/blog/archives/2008/09/a_definition_of.htm 1.

5). Hatherly D. The Failure and the Future of Accounting - Strategy, Stakeholders, and Business Value. Farnham: Gower Publishing Limited; 2013, p. 2.

6). Mihalache A. Cloud Accounting. "Ovidius" University Annals. Economic Sciences Series 2011; XI (2):782-7.

7). Dimitriua,O.,and Mateia, M., A New Paradigm for Accounting through Cloud Computing. Procedia Economics and Finance, Vol.15 (2014), pp.840-846.

8). Dimitriua,O., and Mateia., Cloud accounting: a new business model in a challenging context. Procedia Economics and Finance, Vol. 32 ( 2015),pp. $665-671$

9). Howlett, D., UK cloud accounting in 2013. Diginomica. http://diginomica.com/2013/04/26/ukcloud-accounting-in-2013/

10). Nixon R. The Future of the Accounting Profession - 12 Future Predictions. Proactive Accountants Network. 2012. Available at: http://proactiveaccountants.net. 